\title{
A ROTATIVIDADE DE COLABORADORES NO ESCRITÓRIO DE CONTABILIDADE XXI - TANGARÁ DA SERRA MT
}

\author{
Marcos Fernandes da Silva ${ }^{1}$ \\ Adervaldo Chaves Ribeiro ${ }^{2}$
}

RESUMO: O estudo de caso apresentado, procurou destacar a importância de se entender a rotatividade e o porque de não apenas entender, mas estudar a qualidade da rotatividade após mensurada, se apresenta um nível denominado saudável ou não para o escritório pesquisado. Para obter os dados e mensurar a rotatividade, foi feito uso de pesquisa de campo, onde foi estudado in loco o escritório XXI de Tangará da Serra-MT. Foram entrevistados gestores e colaboradores, personagens fundamentais para a obtenção das informações da pesquisa, além de livros, revistas, e a rede mundial de computadores, utilizados para obter as responsabilidades que recaem sobre os gestores no momento de contratarem ou demitirem seus colaboradores, os encargos trabalhistas, e o que alguns autores estudados chamam de perdas não mensuráveis, que seriam a experiência, rotinas de trabalho e outros. De posse dos resultados obtidos pela pesquisa, foi detectado que não existe um nível de rotatividade a ser evitado ou comparado, mas sim mensurado e analisado os motivos da rotatividade destacada.

Palavra chave: Rotatividade; Escritórios de contabilidade; Colaboradores.

\section{Introdução}

O tema "rotatividade" envolve várias questões que vão além da economia verificada na manutenção do empregado, os benefícios são amplos se for levado em consideração o tempo gasto para se atingir um nível aceitável na prestação do serviço, a continuidade no aprendizado e outros. $\grave{A}$ rotatividade podemos atribuir a falta de incentivos, tanto financeiramente, quanto na falta de planos de carreira no ambiente de trabalho, assim como a desvalorização do profissional, condições físicas, ambientais de trabalho da organização, cultura organizacional, entre outros (WAGNER, 1999).

Toda vez que um colaborador é substituído, tem um tempo de adaptação do novo colaborador, gerando um custo maior de tempo no ambiente de trabalho, e um custo financeiro na saída do anterior. Quando o novo colaborador alcança um nível aceitável na prestação do serviço, torna-se difícil para o gestor avaliar até quanto vale a pena perder recursos humanos para manter uma politica salarial relativamente conservadora e "econômica", ou saber até que nível de rotatividade uma organização pode suportar sem maiores danos (CHIAVENATO, 1997).

\footnotetext{
${ }^{1}$ Acadêmico de Ciências Contábeis - UNEMAT - Tangará da Serra. E-mail: nikitodm@ hotmail.com ${ }^{2}$ Professor de Ciências Contábeis - UNEMAT - Tangará da Serra. E-mail: adervaldo@ unemat.br 
A pesquisa tem como foco estudar a rotatividade em um escritório de contabilidade de Tangará da Serra-MT, no sentido de identificar os motivos que refletem na permuta ou não dos profissionais da área contábil.

Diante disto surgiu o problema: Qual o índice de rotatividade no escritório XXI de contabilidade de Tangará da Serra-MT? Para averiguar a possível resolução do problema fazse o levantamento das seguintes hipóteses:

1- A rotatividade de colaboradores no escritório de contabilidade XXI de Tangará da Serra-MT apresenta alto índice.

2- O índice de satisfação entre os colaboradores, sobre as condições de trabalho oferecidos na empresa apresenta em sua maioria um bom nível.

Tende-se traçar alguns objetivos para se alcançar as hipóteses fixadas, sendo o objetivo geral: Identificar/mensurar qual o índice de rotatividade do escritório de contabilidade XXI de Tangará as Serra-MT. Para alcançar o objetivo geral foram estabelecidos os seguintes objetivos específicos: Caracterizar o escritório estudado; Pesquisar e mensurar a rotatividade existente; Analisar a qualidade da rotatividade apresentada; Verificar se o escritório de contabilidade XXI possui plano de carreira e salários.

A pesquisa trouxe informações que foram pouco difundidas no campus universitário de Tangará da Serra-MT, ofertando opções de pesquisa aos acadêmicos que buscarem conhecer e se atualizarem ao assunto. De acordo com os gestores do escritório pesquisado, a rotatividade influencia diretamente no nível de prestação de serviços oferecidos, assim a pesquisa tornou-se ferramenta leal para o conhecimento e dimensão do quanto a rotatividade influencia em um serviço de qualidade.

O trabalho se justifica haja vista que a sociedade cresce como um todo, assim tem importância por estudar o tema rotatividade pesquisado, e a relevância da manutenção dos recursos humanos, mantendo por consequência a saúde financeira da empresa.

Através das literaturas estudadas foi possível demonstrar também a importância da valorização do profissional e seus colaboradores, com isso buscando refletir os problemas gerados pela rotatividade no ambiente de trabalho. 


\section{Referencial teórico}

\subsection{Rotatividade no contexto contábil}

A contabilidade pode ser conceituada em métodos de identificar, mensurar e comunicar informações econômicas, financeiras, físicas e sociais, permitindo decisões e julgamentos adequados por parte de seus usuários (IUDICÍBUS, 1997).

Contabilidade pode ser também um sistema de informações destinadas a prover dados para ajudar seus usuários a tomar decisões (MARION, 2003).

A maioria da população tem o profissional contábil como um prestador de serviço especializado meramente em satisfazer o fisco, porque tem sido esta a postura da maioria dos profissionais, que aprenderam na própria instituição a copiar fórmulas prontas e rotinas, onde de longe contribui com seu papel na sociedade. A Universidade de Ilinois, que é considerada a número um em contabilidade, inovou o currículo para o curso de Ciências Contábeis, no qual se enfatiza métodos e habilidades que permitam ao aluno questionar, analisar, julgar e tomar decisões (MARION, 2013).

A rotatividade também conhecida no termo inglês como turnover, caracterizada pelo movimento de entradas e saídas, admissões e desligamentos de empregados em uma empresa em um determinado período, podendo ser tanto espontâneo como provocado pela empresa. Pode ocasionar perda de produtividade, lucratividade e saúde dentro da organização, impactando na motivação e compromisso das pessoas que permanecem, influenciando na imagem organizacional (POMI, 2013).

Rotatividade ou Turnover é definida pelo volume de pessoas que ingressam e que saem de uma organização, geralmente expressa por meio de uma relação percentual entre admissões e os desligamentos com relação a média de trabalhadores da organização, em um determinado período de tempo. Normalmente expressa em índices mensais ou anuais permitindo assim comparações para desenvolver diagnósticos, tomar providências ou prevenção (CHIAVENATO, 1997).

É de suma importância analisar os motivos da rotatividade, onde pode ser classificada como funcional ou saudável, quando é do interesse da empresa que o colaborador seja desligado, e disfuncional quando a saída não é de vontade da empresa, mas sim por escolha do colaborador (SILVA, 2002). 


\subsection{Custos da rotatividade}

Muitos empregadores não se dão conta dos custos inerentes a rotatividade, custos que seriam melhor empregados, se direcionados em capacitação ou em melhoramento das condições de trabalho entre outros. O desligamento do colaborador até a contratação do novo geram custos em todo o processo, custos com recrutamento e seleção: gastos com anúncios em jornais, folhetos, testes de seleção e avaliação etc. Custo com treinamento, tempo do supervisor e tempo de integração do novo colaborador. (CHIAVENATO, 1997).

Custo de desligamento: Anotações, registros, comparecimentos a homologações na justiça do trabalho etc. Indenizações pelo tempo anterior à opção pelo FGTS, conforme o caso, custo da antecipação de pagamentos relacionados com férias proporcionais, $13^{\circ}$ salário proporcional, aviso prévio, multa do FGTS etc. (CHIAVENATO, 1997).

\subsubsection{FGTS - Fundo de garantia por tempo de serviço}

Formado por recolhimentos mensais pagos pelo empregador em favor de conta bancária vinculada em nome do empregado, o FGTS tem seu recolhimento obrigatório. Há casos específicos e amparados por lei, como no caso dos domésticos e diretores não empregados, são exceções, pois a regra é a compulsoriedade dos depósitos. (MINISTÉRIO DO TRABALHO, 2011)

\section{LEI N ${ }^{0}$ 6.919, DE 2 DE JUNHO DE 1981.}

Art. $1^{\circ}$ - As empresas sujeitas ao regime da legislação trabalhista poderão estender a seus Diretores não-empregados o regime do Fundo de Garantia por Tempo de Serviço FGTS (JUSBRASIL, 2010).

O FGTS foi instituído pela Lei $n^{\circ}$ 5.107, de 13/09/66. Esta lei foi regulamentada pelo Decreto $\mathrm{n}^{\mathrm{o}} 59.820$, de 20/12/66. Formado por depósitos mensais, efetuados pelas empresas em nome de seus empregados, no valor equivalente ao percentual de $8 \%$ das remunerações que lhes são pagas ou devidas; em se tratando de contrato temporário de trabalho com prazo determinado, o percentual é de $2 \%$, conforme dispõe o inciso II do art. $2^{\circ}$ da Lei $\mathrm{n}^{\circ}$ 9.601, de 21/01/98. Atualmente, a Lei que dispõe sobre o FGTS é a de no 8.036, de 11/05/90, republicada em 14/05/90, já tendo sofrido várias alterações (MINISTÉRIO DO TRABALHO, 2011 ). 
O trabalhador quando demitido sem justa causa, tem direito a receber a multa de $40 \%$ sobre o saldo do FGTS, e aviso prévio de um mês, com redução de duas horas diárias da jornada de trabalho. Agindo assim como uma forma de incentivo à rotatividade. Em muitos casos, o trabalhador força a sua demissão ou faz um acordo com o empregador, onde o trabalhador abre mão de receber a multa, mas nem sempre se desliga da empresa, continua trabalhando sem assinar a carteira de trabalho e previdência social (CTPS), e de forma ilegal recebe do governo o seguro-desemprego. Em casos como este fica evidente que as vezes as políticas de proteção do emprego gera resultados não esperados. Um trabalhador com vários anos de trabalho, prefere receber $140 \%$ do saldo do FGTS sendo demitido, do que permanecer no emprego, e tentar um aumento salarial. A empresa já atenta a este fator, acaba investindo muito pouco em treinamento, pois o risco do término do vínculo empregatício é alto, o que resulta muitas vezes em empregos instáveis e baixos salários (GONZAGA, 1998).

\subsubsection{Gratificação de natal para os trabalhadores $\left(13^{\circ}\right)$}

\section{LEI $\mathrm{N}^{0}$ 4.090, DE 13 DE JULHO DE 1962.}

Art. $1^{\circ}$ - No mês de dezembro de cada ano, a todo empregado será paga, pelo empregador, uma gratificação salarial, independentemente da remuneração a que fizer jus.

$\S 1^{\circ}$ - A gratificação corresponderá a 1/12 avos da remuneração devida em dezembro, por mês de serviço, do ano correspondente.

$\S 2^{\circ}$ - A fração igual ou superior a 15 (quinze) dias de trabalho será havida como mês integral para os efeitos do parágrafo anterior.

$\S 3^{\circ}$ - A gratificação será proporcional: (Incluído pela Lei nº 9.011, de 1995)

Art. $3^{\circ}$ - Ocorrendo rescisão, sem justa causa, do contrato de trabalho, o empregado receberá a gratificação devida nos termos dos parágrafos $1^{\circ}$ e $2^{\circ}$ do art. $1^{\circ}$ desta Lei, calculada sobre a remuneração do mês da rescisão (PLANALTO, 2011).

\subsubsection{FÉRIAS}

\section{DECRETO-LEI No 1.535, DE 15 DE ABRIL DE 1977}


Art. 129 - Todo empregado terá direito anualmente ao gozo de um período de férias, sem prejuízo da remuneração.

Art. 130 - Após cada período de 12 (doze) meses de vigência do contrato de trabalho, o empregado terá direito a férias.

Art. 146 - Na cessação do contrato de trabalho, qualquer que seja a sua causa, será devida ao empregado a remuneração simples ou em dobro, conforme o caso, correspondente ao período de férias cujo direito tenha adquirido.

Art. 147 - O empregado que for despedido sem justa causa, ou cujo contrato de trabalho se extinguir em prazo predeterminado, antes de completar 12 (doze) meses de serviço, terá direito à remuneração relativa ao período incompleto de férias, de conformidade com o disposto no artigo anterior (PLANALTO, 2011).

\subsubsection{1/3 Férias de Abono Obrigatório}

\section{CONSTITUIÇÃO DA REPÚBLICA FEDERATIVA DO BRASIL DE 1988}

Art. $7^{\circ}$ São direitos dos trabalhadores urbanos e rurais, além de outros que visem à melhoria de sua condição social:

XVII - gozo de férias anuais remuneradas com, pelo menos, um terço a mais do que o salário normal (PLANALTO, 2011).

Existem outros aspectos difíceis de avaliar numericamente, por serem intangíveis, onde envolvem mais a questão qualitativa, são efeitos inerentes ao desligamento e contratação do novo colaborador:

Queda de produção ocasionada pelo desligamento do antigo colaborador, que se prolongará até a contratação do novo colaborador. Mesmo após a nova contratação, tem que se levar em conta a questão do tempo que será gasto até o colaborador se adaptar a rotina, 
para a ambientação do novo colaborador, e geralmente a produção costuma ser inferior neste período de adaptação. (CHIAVENATO, 1997).

Sempre que se enfrenta uma nova empreitada de trabalho, o contratado está sob um clima de insegurança, justificável pela ansiedade e a dúvida se gostarão do seu trabalho, se conseguirá desempenhar bem o seu trabalho. (CHIAVENATO, 1997).

O novo colaborador se sente desconfortável em ter que pedir auxílio a outros colaboradores, auxílio este inevitável, já que mesmo que se tenha a experiência devida da profissão, não se sabe os processos usados pela entidade. (CHIAVENATO, 1997).

A imagem da entidade também pode ficar afetada, tanto para os clientes, como para os demais colaboradores, principalmente se a rotatividade tiver uma certa constância. È normal que os colegas de trabalho e clientes da entidade, que dependiam do antigo colaborador questionem o por que da saída do mesmo, e aqui fica um ponto delicado, já que as interpretações podem ser das mais variadas sobre a moral e atitudes do chefe. (CHIAVENATO, 1997).

Outros custos que podem ser mensurados, mas raramente os são pela demanda de tempo:

O valor que se gasta de horas extras, para cobrir a vaga existente, ou para cobrir a deficiência inicial do novo empregado, tempo adicional para o desempenho de tarefas, que podem elevar os custos de energia elétrica, desgaste maior de equipamentos e materiais de trabalho. (CHIAVENATO, 1997).

A rotatividade de pessoal - pelos seus inúmeros e complexos aspectos negativos quando acelerada, torna-se um fator de perturbação. Principalmente quando forçada pelas empresas no sentido de obtenção de falsas vantagens a curto prazo, o certo é que a médio e longo prazos a rotatividade provoca enormes prejuízos à organização, ao mercado e à economia como um todo - e, principalmente, ao empregado tomado individual ou socialmente em relação à sua família (CHIAVENATO, 1997).

\subsection{O salário como fator mais relevante na rotatividade}

A compensação é provavelmente a principal razão pela qual as pessoas buscam um emprego. Ela é importante do ponto de vista de cada pessoa, como uma necessidade vital. Pagamento é o meio pelo qual uma pessoa, como proporciona satisfação de suas necessidades e das de sua família. Para muitas pessoas com atitude instrumental quanto ao trabalho, ela é a principal razão para trabalhar. Porém, o trabalho pode ser mais do que um elemento que proporcione satisfação para as necessidades fisiológicas das pessoas. A compensação define o nível de importância de uma pessoa para sua organização (CHIAVENATO 1997). 
Um estudo feito sobre rotatividade no Brasil, onde foram entrevistados 150 profissionais com mais de 25 anos, demonstra que quando a demanda por profissionais chega a ser maior que a oferta oferecida pelo mercado, gera inflações de salários, trazendo assim grandes desafios para as empresas, onde sentem dificuldades em atrair e reter os profissionais. No estudo, mais de $60 \%$ dos entrevistados afirmam que o tempo de permanência das pessoas nas empresas tem sido menor, uma das explicações alcançadas que merece destaque, é a busca dos mais jovens por posições mais altas e rapidamente, e quando a empresa não consegue suprir esta necessidade, a tendência é que este profissional saia assim que tenha oportunidade (QUÉGE, 2013).

\begin{abstract}
Há também uma distinção entre salário nominal e salário real. O salário nominal representa o volume de dinheiro fixado em contrato individual pelo cargo ocupado. Em uma economia inflacionária, o salário nominal, quando não é atualizado periodicamente, sofre erosão. O salário real representa a quantidade de bens que o empregado pode adquirir com aquele volume de dinheiro e corresponde ao poder aquisitivo, ou seja, o poder de compra, a quantidade de mercadorias que pode ser adquirida com o salário. Assim, a mera reposição do valor real não significa aumento salarial: o salário nominal é alterado para proporcionar salário real equivalente em período anterior. Daí a distinção entre reajustamento do salário (recomposição do salário real) e aumento real do salário (acréscimo do salário real) (CHIAVENATO, 1997)
\end{abstract}

O País detém uma das maiores cargas tributárias do mundo, o que contribui para o aumento dos produtos objeto de desejo de todos. Mesmo os salários diretos pagos aos funcionários em muitos casos inferiores a outros Países, os encargos cobrados sobre os salários são altíssimos (BETING, 1996).

Mas o salário não caracteriza o único motivo da rotatividade, porem é um dos primeiros fatores a se levar em conta pelo colaborador na hora de abandonar o emprego. Outros aspectos importantes na decisão de sair do emprego é o sistema de recompensas oferecido pela entidade. Benefícios sociais, incentivos pelo desempenho do colaborador, oportunidade de crescimento na entidade, estabilidade, etc. (OZAKI; ALVES. 2009).

Os salários têm vários desdobramentos do ponto de vista legislativo e fiscal. Geram encargos sociais que são calculados sobre seus valores em uma verdadeira cascata. É que incidem sobre os salários todos os cálculos sobre a previdência social, sobre o Fundo de Garantia por Tempo de Serviço e outros encargos que são suportados e pagos pela organização quando esta remunera seus empregados. Os encargos envolvem obrigações sociais, tempo não trabalhado pelo empregado, bem como o reflexo dos itens anteriores devido ao efeito de cascata. (CHIAVENATO, 1997).

De acordo com a Federação da indústrias no Estado de Mato Grosso (FIEMT), em

2.011, Mato Grosso ampliou seu volume de empregos formais em 8,05\%, o maior avanço 
relativo ao Centro-Oeste, mas a renda média dos trabalhadores cresceu apenas $3,22 \%$, a segunda em evolução, o que demonstra claramente a baixa qualificação da mão-de-obra. Os melhores resultados em números foi observado no segmento de serviços, com geração de 14,1 mil postos de trabalho 9,61\%. Mato Grosso apresenta uma média de renda $11,78 \%$ inferior segundo dados da Relação Anual de Informações Sociais (RAIS). A média Nacional passou de $\mathrm{R} \$ 1.847,92$ para $\mathrm{R} \$ 1.902,13$, alta de 2,93\%. No Mato Grosso passou de $\mathrm{R} \$ 1.626,11$ para $1.678,45,(3,22 \%)$.

Quadro 1

\begin{tabular}{|l|c|c|r|r|r|r|r|r|r|}
\hline \multicolumn{7}{|c|}{ COMPARATIVO DA RAIS BRASIL E MATO GROSSO, POR SETORES DE ATIVIDADES } \\
\hline & \multicolumn{2}{|c|}{ Mato Grosso } & \multicolumn{2}{c|}{ Variação } & \multicolumn{2}{c|}{ Brasil } & \multicolumn{2}{c|}{ Variação } \\
\hline Setores de Atividades & 2010 & 2011 & Absoluta & Relativa & 2010 & 2011 & Absoluta & Relativa \\
\hline Indústria & 134.194 & 143.467 & 9.273 & $6,91 \%$ & 11.008 .124 & 11.508 .108 & 499.984 & $4,54 \%$ \\
\hline Serviços & 146.968 & 161.090 & $\mathbf{1 4 . 1 2 2}$ & $\mathbf{9 , 6 1 \%}$ & 14.345 .015 & 15.372 .455 & 1.027 .440 & $7,16 \%$ \\
\hline Outros & 375.380 & 404.820 & 29.440 & $7,84 \%$ & 18.715 .216 & 19.430 .068 & 714.852 & $3,82 \%$ \\
\hline Total Geral & 656.542 & 709.377 & 52.835 & $\mathbf{8 , 0 5 \%}$ & 44.068 .355 & 46.310 .631 & 2.242 .276 & $5,09 \%$ \\
\hline
\end{tabular}

(FIEMT, 2012)

Os encargos sociais no Brasil são elevados a tal patamar, que faz com que os salários em nosso País, embora baixos, representem valores muito altos se comparados a outros países. (BETING, 1996).

Tabela 1- Comparação feita pela Booz-Allen \& Hamilton nas montadoras de automóveis, pelos critérios brasileiros, para cargos horistas (Base: 8 horas diárias de trabalho):

\begin{tabular}{ll}
\hline Brasil: & US\$ 1,66 por US\$ 1,00 de salário-hora \\
Itália: & US\$ 1,12 \\
França: & US\$ 0,88 \\
Alemanha: & US\$ 0,76 \\
Estados Unidos: & US\$ 0,34 \\
Japão: & US\$ 0,31 \\
Comparação do salário-hora médio pago nas empresas montadoras de automóveis: \\
Brasil: & US\$ 3,00 \\
Inglaterra: & US\$ 12,00 \\
Japão: & US\$ 13,00 \\
Estados Unidos: & US\$ 15,00 \\
Itália: & US\$ 16,00 \\
Alemanha: & US\$21,00
\end{tabular}

BETING, 1996).

Por essa razão, embora os salários diretos pagos aos funcionários ainda sejam muito inferiores aos de outros países, nossas empresas acabam tendo um custo de mão-deobra muito maior devido à forte incidência de encargos sociais, elevando o chamado custo Brasil (CHIAVENATO, 1997).

\subsection{Custo Brasil}


O Custo Brasil é um termo genérico, usado para descrever o conjunto de dificuldades que encarecem o investimento no Brasil, dificultando-lhe o crescimento e o desenvolvimento. (ARTIGONAL, 2010)

E quais são os custos que compõem a formação de preço de um produto e por que eles são mais elevados no país? (ARTIGONAL, 2010).

O investidor faz suas contas para verificar qual país tem mais condições de lhe render um lucro maior em sua produção, levando em consideração diversos fatores. (ARTIGONAL, 2010).

Os tributos Federais, Estaduais e Municipais, provocaram recordes de arrecadação nos últimos anos. No ano 2.000 chegou a 32,34\% do Produto interno Bruto, aumentando a indústria de arrecadação e fiscalização, e com isso onerando os custos necessários a sua apuração e recolhimento. Afetando governo e empresários pelo excesso de tributos em vigor (OLIVEIRA, 2004).

Várias campanhas tem clamado por mudanças no Sistema Tributário Nacional, que passa por uma revisão de texto constitucional. Sugestões radicais como a possibilidade de um imposto único e outras mais racionais como a redução da quantia de tributos, mantendo a tributação sobre a renda, consumo e a propriedade, simplificando assim o processo (OLIVEIRA, 2004).

\section{Metodologia}

A pesquisa foi realizada em um escritório de contabilidade na cidade de Tangará da Serra-MT. Foi elaborado questionários com questões mistas direcionadas aos gestores e colaboradores, o que VERGARA (2000) entende como pesquisa de campo, por ser desenvolvida no escritório citado, no qual se fez necessário pesquisar o número de colaboradores que entraram e saíram no período de 01/01/2010 à 31/12/2012. Considera-se pesquisa de campo a investigação empírica realizada no local onde ocorre ou ocorreu um fenômeno ou que dispõe de elementos para explicá-lo (VERGARA, 2000).

Oportunamente, a pesquisa também foi documental, pois valeu-se de documentos fornecidos pelo escritório pesquisado, os documentos em questão, são planilhas de rotatividade obtidos em visita feita in loco no escritório XXI, onde por meio do colaborador responsável, teve-se acesso aos relatórios de entradas e saídas de colaboradores no período de 01/01/2010 a 31/12/2012. Tais documentos são oriundos do programa contábil (DOMÍNIO) 
usado pelo escritório pesquisado, ou por meio de relatórios informados ao Governo (Cadastro Geral de Empregados e Desempregados), além de livros e revistas, também foi feito pesquisas na rede mundial de computadores, o que se entende por pesquisa telematizada, para o entendimento e exemplos de cálculos para medir a rotatividade, que serão aplicados nos resultados da pesquisa, caracterizando-se assim de uma pesquisa bibliográfica. O estudo sistematizado desenvolvido com base em material publicado em livros, revistas, jornais, redes eletrônicas, isto é, material acessível ao público em geral é pesquisa bibliográfica (VERGARA 2000).

Para desenvolver o estudo, foi pesquisado o escritório de contabilidade XXI de Tangará da Serra-MT. É limitado a uma ou poucas unidades o estudo de caso, entendidas essas como, uma família, um produto, uma empresa, um órgão público, uma comunidade ou mesmo um país. Tem caráter de profundidade e detalhamento (VERGARA, 2000).

\subsection{Informações sobre a organização}

O escritório XXI está situado a rua 1 no município de Tangará da Serra MT. Atua no ramo da contabilidade a mais de 25 (vinte e cinco) anos, e seus proprietários possuem graduação em contabilidade. Os gestores também afirmam possuir excelência na prestação de serviços oferecidos. A empresa encontra-se hoje com 13 colaboradores em seu quadro de funcionários. Segundo os gestores a empresa não possui plano de carreira, e através do questionário afirmaram oferecer uma remuneração estratégica baseada em desempenho e por departamentos, admitiram não possuir qualquer tipo de controle sobre a rotatividade, e disseram mesmo assim que a maioria dos colaboradores demitidos apresentavam baixo desempenho, o que é caracterizado segundo (SILVA, 2002) como uma rotatividade funcional ou saudável. Seguindo a mesma linha de pensamento (CHIAVENATO, 1.997) afirma que o índice ideal de rotatividade, é quando substitui-se apenas aqueles que apresentam distorções de desempenho.

Os dados da pesquisa realizada na empresa entre 14 e 21 de setembro de 2.013 , foram mensurados, interpretados, analisados e apresentados por meio de tabelas.

\section{Discussão dos resultados}

Através da pesquisa realizada no escritório XXI de contabilidade na cidade de Tangará da Serra-MT descrito neste estudo de caso, onde foram analisados documentos contendo entradas e saídas de colaboradores no período de 01/01/2010 a 31/12/2012, e aplicado a 
fórmula de rotatividade proposta no trabalho (CHIAVENATO, 1997, p. 188), identificou-se que, o nível de rotatividade no último ano pesquisado se encontra em 15,5\%, bem abaixo dos níveis anteriores, porém se analisado em um contexto geral, os três anos apresentam um nível alto de rotatividade se comparado ao último ano, 106,67\%.

Tabela 2- Rotatividade dos últimos três anos.

\begin{tabular}{cccccc} 
ANO & Empregados inicio & Desligamentos & Admissões & Empregados final & Rotatividade \% \\
\hline 2010 & 13 & 4 & 6 & 15 & 35,71 \\
2011 & 15 & 8 & 9 & 16 & 54,84 \\
2012 & 16 & 2 & 3 & 17 & 15,15 \\
$2010 / 2012$ & 13 & 14 & 18 & 17 & 106,67 \\
\hline
\end{tabular}

Fonte: Dados da pesquisa.

No período estudado, a empresa em virtude das demandas, teve uma expansão no seu nível de colaboradores, o que também contribui para aumentar o nível de rotatividade, o que observamos quando o número de colaboradores salta de 13 (treze) em 2.010 para 17 (dezessete) em 2.012, demonstrando assim que mesmo que não se demita nenhum colaborador e se contrate outros, haverá ainda assim rotatividade.

Para o cálculo de rotatividade é baseado o volume de entradas e saídas de pessoal, dentro de certo período de tempo, e em termos percentuais. Quando se trata de medir o índice de rotatividade de pessoal, utiliza-se a seguinte equação: $A+D / 2 * 100 / E M$, onde: $A=$ admissão de pessoal; $\mathrm{D}$ = desligamento de pessoal e $\mathrm{EM}$ = efetivo médio, obtido pela soma dos efetivos existentes no início e no final do período, dividida por dois (CHIAVENATO 1997).

Só para se exemplificar o funcionamento da fórmula proposta, ainda que não houvesse demissão, assim mesmo haveria um índice de rotatividade. Considere no inicio do período um efetivo de 13 (treze) colaboradores, demissões iguais a 0 (zero), e admissões iguais a 18 (dezoito), e colaboradores no final do período 31, aplicando os fatores a fórmula estudada teremos um índice de: $(((18+0) / 2 * 100) / 22)=40,91 \%$ de rotatividade. Observe que mesmo não havendo nenhuma demissão, ainda assim a rotatividade foi de $40,91 \%$, o que nos leva a entender que o acompanhamento da rotatividade é importante, e ainda mais importante é entender se ela é saudável ou não para a empresa.

$\mathrm{O}$ índice de rotatividade considerado ideal, seria aquele que permitisse à organização reter seu pessoal de boa qualidade que não apresentam distorções de desempenho, e aquelas 
pessoas que apresentam distorções de desempenho difíceis de ser corrigido, serem substituídas (CHIAVENATO, 1997).

\subsection{Análise dos questionários}

Os dados a seguir são resultados obtidos através da pesquisa realizada no escritório de contabilidade XXI conforme já mencionado.

Tabela 3- Tempo de trabalho na área contábil.

\begin{tabular}{lcl}
\hline & Quantidade & $\%$ \\
\hline Menos de 1 ano & 1 & 9 \\
De 2 a 3 anos & 1 & 9 \\
De 4 a 5 anos & 4 & 36 \\
Mais de 6 anos & 5 & 46 \\
TOTAL & $\mathbf{1 1}$ & $\mathbf{1 0 0}$ \\
\hline
\end{tabular}

Fonte: Dados da pesquisa.

Como pode-se observar, 9 (nove) colaboradores ou seja $82 \%$ (oitenta e dois por cento), atuam na área contábil há mais de quatro anos.

Tabela 4- Tempo de trabalho na empresa.

\begin{tabular}{lcl}
\hline & Quantidade & $\%$ \\
\hline Menos de 2 anos & 2 & 18 \\
De 3 a 4 anos & 4 & 36,5 \\
De 5 a 6 anos & 1 & 9 \\
Mais de 7 anos & 4 & 36,5 \\
TOTAL & $\mathbf{1 1}$ & $\mathbf{1 0 0}$ \\
\hline
\end{tabular}

Fonte: Dados da pesquisa.

Em sua grande maioria, 9 (nove) colaboradores, ou $82 \%$ (oitenta e dois por cento) dos entrevistados, trabalham na empresa a mais de três anos.

Tabela 5- Tempo de desempenho da função no atual setor.

\begin{tabular}{lcl}
\hline & Quantidade & $\%$ \\
\hline Menos de 1 ano & 1 & 9 \\
De 2 a 3 anos & 4 & 37 \\
De 4 a 5 anos & 3 & 27 \\
Mais de 6 anos & 3 & 27 \\
TOTAL & $\mathbf{1 1}$ & $\mathbf{1 0 0}$ \\
\hline
\end{tabular}

Fonte: Dados da pesquisa.

A maioria dos entrevistados, 6 (seis), o que representa 54\% ( cinquenta e quatro por cento), trabalham a mais de 4 (quatro) anos no mesmo setor, demonstrando que a empresa costuma contratar colaboradores para setores específicos, exemplo: fiscal, contábil, recursos humanos. Havendo assim pouca movimentação entre os setores.

\begin{tabular}{lr}
\hline Volume 3, Número 5 & Revista UNEMAT de Contabilidade \\
Jan./Jun. 2014 & UNEMAT
\end{tabular}


Tabela 6- Avaliação das condições de trabalho.

\begin{tabular}{lcl}
\hline & Quantidade & $\%$ \\
\hline Ruins & 0 & 0 \\
Regulares & 3 & 27 \\
Boas & 7 & 64 \\
Ótimas & 1 & 9 \\
TOTAL & $\mathbf{1 1}$ & $\mathbf{1 0 0}$ \\
\hline
\end{tabular}

Fonte: Dados da pesquisa.

Os dados demonstram que em sua maior parte 8 (oito), representando $73 \%$ (setenta e três por cento) dos colaboradores, consideram as condições de trabalho oferecidas boas ou ótimas. Apesar de as condições de trabalho em sua maior parte serem consideradas boas ou ótimas, os gestores devem se preocupar com os $27 \%$ (vinte e sete por cento) que acham as condições oferecidas regulares, pois futuramente pode se tornar um fator de desconforto para a empresa.

Tabela 7- Investimento em qualificação pela empresa.

\begin{tabular}{lcl}
\hline & Quantidade & $\%$ \\
\hline Sim & 5 & 45 \\
Não & 6 & 55 \\
TOTAL & $\mathbf{1 1}$ & $\mathbf{1 0 0}$ \\
\hline
\end{tabular}

Fonte: Dados da pesquisa.

Também foi constatado que, o investimento em qualificação na empresa esta abaixo do esperado, já que 6 (seis) colaboradores, representando 55\% (cinquenta e cinco por cento), disseram que a empresa não investe neste item.

Tabela 8- Cursos disponibilizados ao ano.

\begin{tabular}{lcc}
\hline & Quantidade & $\%$ \\
\hline Até 1 & 2 & 45 \\
De 2 a 3 & 3 & 55 \\
De 4 a 5 & 0 & 0 \\
Acima de 6 & 0 & 0 \\
TOTAL & $\mathbf{5}$ & $\mathbf{1 0 0}$ \\
\hline
\end{tabular}

Fonte: Dados da pesquisa.

Dos colaboradores que responderam na tabela anterior que a empresa investe em qualificação, 3 (três) deles totalizando 55\% (cinquenta e cinco por cento), afirmam que a empresa disponibiliza de 2 (dois) a 3 (três) cursos ao ano. 
Tabela 9- Nível de formação contábil.

\begin{tabular}{lcl}
\hline & Quantidade & $\%$ \\
\hline Técnico & 2 & 18 \\
Graduação & 8 & 73 \\
Especialização & 1 & 9 \\
Mestrado/doutorado & 0 & 0 \\
TOTAL & $\mathbf{1 1}$ & $\mathbf{1 0 0}$ \\
\hline
\end{tabular}

Fonte: Dados da pesquisa.

Percebe-se na pesquisa, que o nível de formação na área contábil em sua menor parte esta em nível técnico, 2 (dois) entrevistados ou $18 \%$ (dezoito por cento), seguido por 8 (oito) que representam a maior parte, sendo $73 \%$ (setenta e três por cento) dos colaboradores, e 1 (um) colaborador, equivalente a 9\% (nove por cento) no nível de especialização.

Tabela 10- Nível de qualificação desejada.

\begin{tabular}{lcc}
\hline & Quantidade & $\%$ \\
\hline Satisfeito & 0 & 0 \\
Graduação & 1 & 8 \\
Especialização & 6 & 59 \\
Mestrado/doutorado & 3 & 25 \\
Não respondeu & 1 & 8 \\
TOTAL & $\mathbf{1 1}$ & $\mathbf{1 0 0}$ \\
\hline
\end{tabular}

Fonte: Dados da pesquisa.

A maioria busca uma melhor qualificação e aprendizado na área contábil, apenas 1 (um) colaborador ou 8\% (oito por cento) procura uma graduação, enquanto a maioria 6 (seis) representando $59 \%$ (cinquenta e nove por cento) buscam uma especialização, seguido de 3 (três) colaboradores que representam 25\% (vinte e cinco por cento) querem um mestrado/doutorado e 1 (um) colaborador ou $8 \%$ (oito por cento), não respondeu.

Tabela 11- Opinião sobre possível aumento de renda com uma melhor qualificação.

\begin{tabular}{lcl}
\hline & Quantidade & $\%$ \\
\hline Sim & 8 & 73 \\
Não & 3 & 27 \\
TOTAL & $\mathbf{1 1}$ & $\mathbf{1 0 0}$ \\
\hline
\end{tabular}

Fonte: Dados da pesquisa.

Os dados mostram que 8 (oito) entrevistados, que correspondem a 73\% (setenta e três por cento) na tabela, disseram que a sua renda aumentaria com uma melhor qualificação. Os $27 \%$ que votaram não, ficam em dúvida sobre esta melhoria. 
Tabela 12- Faixa salarial.

\begin{tabular}{lcl}
\hline & Quantidade & $\%$ \\
\hline Até R\$ 1.000,00 & 0 & 0 \\
De R \$ 1.001,00 até R \$ 2.000,00 & 6 & 55 \\
De R $2.001,00$ até R \$ 3.000,00 & 2 & 18 \\
Mais de R 3.001,00 & 3 & 27 \\
TOTAL & $\mathbf{1 1}$ & $\mathbf{1 0 0}$ \\
\hline
\end{tabular}

Fonte: Dados da pesquisa.

Também foi foco de investigação a faixa salarial dos colaboradores, onde a maioria 6 (seis) colaboradores ou 55\% (cinquenta e cinco por cento), recebem acima de $\mathrm{R} \$ 1.001,00$ até $\mathrm{R} \$ 2.000,00$, enquanto que 2 (dois) representando 18\% (dezoito por cento), recebem de 2.001,00 até $\mathrm{R} \$ 3.000,00$, e 3 (três) colaboradores ou 27\% (vinte e sete por cento), recebem acima de $\mathrm{R} \$ 3.001,00$ reais.

Tabela 13- Cruzamento de dados (Qualificação x Faixa Salarial).

\begin{tabular}{lcc}
\hline & Quantidade & $\mathrm{R} \$$ \\
\hline Nível técnico & 2 & 1.001 a 2.000 \\
Especialização & 1 & 1.001 a 2.000 \\
Graduação & 3 & 1.001 a 2.000 \\
Graduação & 2 & 2.001 a 3.000 \\
Graduação & 3 & mais de 3.000 \\
\hline TOTAL & $\mathbf{1 1}$ & $\mathbf{1 0 0 \%}$ \\
\hline
\end{tabular}

Fonte: Dados da pesquisa.

Feito um cruzamento de dados entre a tabela 7 (sete) Nível de formação contábil, e tabela 10 (dez) faixa salarial, fica claro que os colaboradores com nível técnico, tem remuneração igual ao colaborador com nível de especialização.

O resultado deste cruzamento, mostra que a empresa não remunera os colaboradores por nível de formação, e sim por tempo de atuação na empresa, já que existem funcionários de nível técnico, sendo remunerado da mesma forma daqueles com graduação ou especialização. Justificando assim os resultados da tabela 9, onde $27 \%$ dos entrevistados afirmaram não acreditar em uma melhora salarial com uma qualificação maior.

Contribuindo com o estudo, buscou-se informações em pesquisa denominada: Qualidade de vida no trabalho. Um estudo de caso numa empresa de contabilidade em Anápolis/GO (GOOGLE ACADÊMICO, 2013). Comparado com a pesquisa aqui apresentada, a tabela 4 (quatro), no qual foi analisado as condições de trabalho, foi detectado que a maioria $73 \%$ (setenta e três por cento) dos colaboradores, consideraram satisfeitos com as condições de trabalho, na pesquisa comparada ocorreu o inverso , 57\% (cinquenta e sete 
por cento) dos entrevistados estão insatisfeitos. Afim de auxiliar e agregar resultados a pesquisa apresentada, os colaboradores das duas pesquisas opinaram sobre mudanças que poderiam ocorrer para melhorar o ambiente de trabalho.

Figura 1- Sugestões de melhoras.

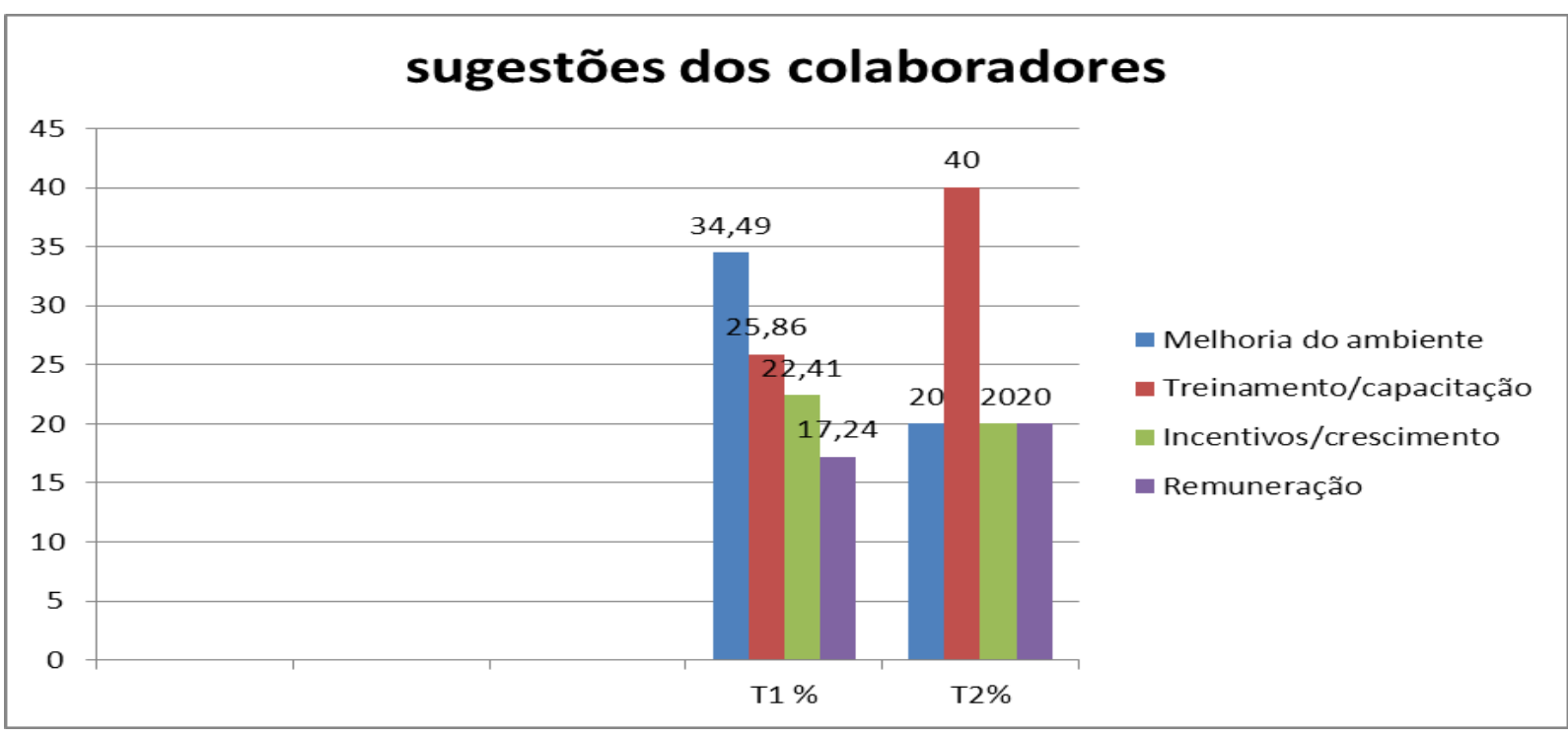

Fonte: Dados da pesquisa.

T1- pesquisa comparada e T2- pesquisa apresentada.

Dos colaboradores que opinaram na pesquisa comparada (T1), 34,49\% (trinta e quatro virgula quarenta e nove por cento) dos colaboradores, preferem melhorias no ambiente de trabalho, enquanto que na pesquisa apresentada, são $20 \%$ (vinte por cento), 25,86\% (vinte e cinco virgula oitenta e seis por cento), preferem treinamento em (T1), ao passo que em em (T2), são $40 \%$ (quarenta por cento). Incentivos em (T1) são $22,41 \%$ (vinte e dois virgula quarenta e um porcento) e em (T2) 20\% (vinte por cento). Tal quesito pode ser resolvido pelo menos em parte, com um plano de carreira e remuneração estratégica bem definidos. A remuneração aparece em (T1) com 17,24\% (dezessete virgula vinte e quatro por cento) e em (T2) $20 \%$ ( vinte por cento).

A figura apresentada demonstra que apenas remuneração não basta para um ambiente de qualidade, os colaboradores opinaram antes em outros aspectos, portanto um planejamento se faz necessário, e uma pesquisa mais detalhada, focado na qualidade que pretendem alcançar, e assim definir metas para alcançar e reter o capital humano no escritório, evitando assim futuras demissões.

\section{Considerações finais}

Através da pesquisa e analise das informações coletadas, confirmou-se a hipótese 1 (um) descrita no trabalho, demonstrando que o índice de rotatividade apresentado no período 
estudado é alto. Independente da rotatividade apresentada, o mais importante aprendizado adquirido na bibliografia estudada é que, o que se deve analisar com maior critério é se a rotatividade é funcional (saudável) para a empresa, onde os colaboradores afastados apresentavam problemas no desempenho de suas funções, porém através dos dados levantados com a pesquisa surgiu o seguinte dilema, que pode servir para continuação do trabalho apresentado: e se o problema no desempenho do colaborador, for questões referentes ao ambiente de trabalho, falta de equipamentos adequados e melhores, ou até mesmo convivência conturbada entre colaboradores e gestores?. Os colaboradores podem propositalmente, diminuir seu ritmo de trabalho e apresentar deficiência em outras atividades, onde para a empresa seria uma justificativa óbvia de rotatividade saudável, onde na verdade o colaborador não se sentindo satisfeito no ambiente de trabalho, forçou a própria queda de empenho. A hipótese 2 (dois) também foi comprovada com os índices apresentados na tabela 4 (quatro), onde a maioria $73 \%$ (setenta e três por cento) dos colaboradores, consideram as condições de trabalho como boas ou ótimas, sendo assim um bom nível. Quanto aos objetivos, o escritório XXI foi caracterizado no título 3.1 do artigo. A pesquisa foi realizada e mensurou-se a rotatividade existente, que apresentou um índice elevado no período pesquisado se comparado ao último ano. Segundo os gestores, a maioria dos colaboradores demitidos apresentavam baixo desempenho, sendo assim uma rotatividade funcional ou positiva. Os gestores também afirmaram não possuir plano de carreira, e oferecem uma remuneração estratégica, baseada em desempenho e por departamentos.

É preciso destacar, a influência do FGTS na rotatividade de colaboradores demonstrada no trabalho, onde a multa funciona como um incentivo neste processo, o que compromete em parte a fidelidade de informações, já que colaboradores e patrões concordam em praticar acertos, informando saídas e entradas que as vezes não ocorreram, muitos podem erroneamente pensar que o governo com suas ações, tais como cursos obrigatórios em horário de trabalho para aqueles que se encontram desempregados, podem impedir manobras que já ocorrem, como descontar as férias enquanto o colaborador demitido de fachada, participa de tais qualificações. A mudança de comportamento deve ser feita e seguida tendo como exemplos empresas com níveis de excelência, onde tais processos são abomináveis, para tanto a mudança cultural deve ter partida através de estudos e exemplos a serem seguidos. Tais informações são utilizadas pelo Governo para tomada de decisões, que são comprometidas pela falta de informações confiáveis que são informadas pelos próprios prejudicados com as decisões tomadas pelo poder público. 


\section{Referências bibliográficas}

ARTIGONAL. O Custo Brasil. Disponível em: < http://www.artigonal.com/direitotributario-artigos/custo-brasil-1071713.html> Acesso em: 20 de setembro de 2010.

CHIAVENATO, Idalberto. Recursos Humanos. 6ª ed. São Paulo: Atlas, 1997.

Fiemt. comparativo da RAIS. Disponível em:

<http://www.fiemt.com.br/hotsites/fiemt/news_indicadores_agosto2012/news_indicadores_ag osto-2012.pdf.> Acessado em: 20 de agosto de 2012.

GONZAGA, Gustavo. Rotatividade e qualidade do emprego. Revista de economia politica, vol. 18, n. 69, p. 120-135, março. 1998.

GOOGLE, Acadêmico. Qualidade de Vida no Trabalho. Disponível em:

$<$ http://www1.unievangelica.edu.br/gc/imagens/file/Microsoft\%20Word\%20-

\%20ArtigoPublica\%E7\%E3oJulianaDelFiaco1.pdf> Acessado em: 15 de novembro de 2013.

IUDÍCIBUS, Sérgio de. Teoria da Contabilidade. São Paulo: Atlas, 1997.

MARION, Carlos José. A Importância da Pesquisa no Ensino da Contabilidade .

Disponível em:

$<$ http://www.marion.pro.br/portal/modules/wfdownloads/visit.php?cid=2\&lid=8 > Acesso em: 01 de abril. 2013.

MARION, Carlos José. Contabilidade Empresarial. 10ª ed. São Paulo: Atlas, 2003.

MTE. Ministério do Trabalho e Emprego. Instituição do FGTS. Disponível em: <http://www.mte.gov.br/fgts/oquee.asp> Acesso em: 19de agosto de 2011.

OLIVEIRA Luis Martins de. Manual de contabilidade tributária. $3^{\text {a }}$ Ed. São Paulo: Atlas, 2004.

OSAKI. Y; ALVES. F. Em busca da gestão estratégica da rotatividade de pessoal. Revista de ciências gerais, vol. 13, n. 18, p. 163-176, setembro, 2009.

PLANALTO. Gratificação de Natal Para os Trabalhadores. Disponível em : <http://www.planalto.gov.br/ccivil_03/Leis/L4090.htm> Acesso em: 19 de agosto de 2011.

PLANALTO. Do Direito a Férias e da sua Duração. Disponível em :

<http://www.planalto.gov.br/ccivil/decreto-lei/Del1535> Acessado em: 19 de agosto de 2011.

PLANALTO. Férias com um terço a mais que o salário normal. Disponível em:

<http://www.planalto.gov.br/ccivil_03/constituicao/constitui\%C3\%A7ao.htm>Acesso em: 19 de agosto de 2011. 
QUÉGE, M. A. Estudo Sobre Rotatividade no Brasil. Disponível em:

<http://www.bsp.edu.br> Acesso em: 04 de setembro. 2013.

POMI, R. M. recursos humanos. Disponível em: 〈http://www.pesquisabrasileira.com.br> Acesso em: 01 de setembro. 2013.

SILVA, M. F. Comportamento organizacional: a rotatividade em foco. Revista da psicologia da Universidade Federal do Ceará, Ceará, vol. 20, n. 2. 2002.

VERGARA, Sylvia Constant. Projetos e Relatórios de Pesquisa em Administração. $3^{\mathrm{a}}$ Ed. São Paulo: Atlas, 2000.

WAGNER, John. Comportamento organizacional. São Paulo: Saraiva, 1999. 